Supplement of Saf. Nucl. Waste Disposal, 1, 245-246, 2021

https://doi.org/10.5194/sand-1-245-2021-supplement

(c) Author(s) 2021. CC BY 4.0 License.

Supplement of

\title{
EURAD School of Radioactive Waste Management
}

Niels Belmans and Michèle Coeck

Correspondence to: Niels Belmans (nbelmans@sckcen.be)

The copyright of individual parts of the supplement might differ from the article licence. 


\section{EURAD SCHOOL OF RADIOACTIVE WASTE MANAGEMENT}

BASE Interdisciplinary Research Symposium, Session 4B 10 November 2021 • Niels Belmans

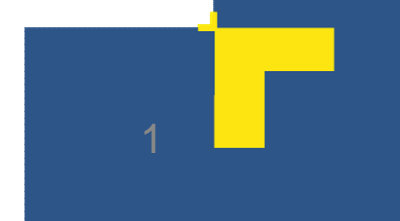




\section{EURAD KNOWLEDGE MANAGEMENT \& NETWORKING PROGRAMME}

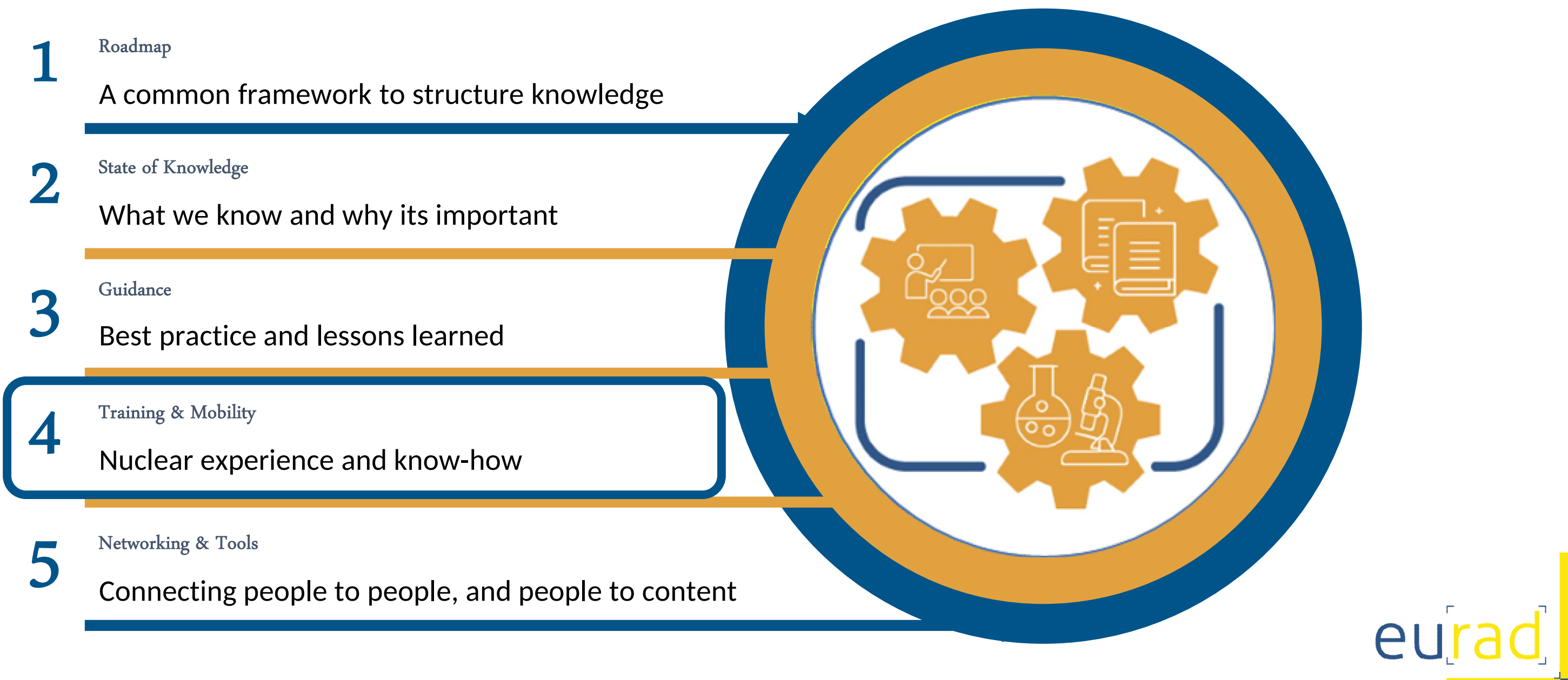




\section{EURAD KNOWLEDGE MANAGEMENT \& NETWORKING PROGRAMME}

IAEA defines knowledge management (KM) as:

“an integrated, systematic approach to identifying, acquiring, transforming, developing, disseminating, using, sharing and preserving knowledge, relevant to achieving specified objectives"*

$\rightarrow$ “Enhance knowledge management and transfer” is one of EURAD's main objectives

$\rightarrow$ EURAD Knowledge Management \& Networking Programme

- Cohesive programme

- Important for the safety of (geological) waste disposal, now and in the future 


\section{EURAD SCHOOL OF RADIOACTIVE WASTE MANAGEMENT}

- The School of Radioactive Waste Management (RWM) aims to assist end-users in:

- "an integrated, systematic approach to identifying, acquiring, transforming, developing, disseminating, using, sharing and preserving knowledge (and skills), relevant to achieving specified objectives"

- To this end, the School supports competence (= knowledge, skills and attitudes) building through:

- A portfolio of needs-driven training courses (and gaps in the Roadmap)

- A dedicated Mobility Programme

- Organization of webinars on broad and specific topics by subject-matter experts

- Maintaining a library of webinar recordings

- Support for the EURAD PhD community

- Host a discussion forum to reinforce networking within the 'EURAD family'

$\rightarrow$ Centralized on a dedicated website: https://euradschool.eu/ 


\section{EURAD SCHOOL OF RADIOACTIVE WASTE MANAGEMENT}

The School of RWM's end-users are:

- (Junior/Senior) Professionals

- PhD students

- Post-docs

- Students

- Civil Society 
THE EURAD SCHOOL OF RADIOACTIVE WASTE MANAGEMENT

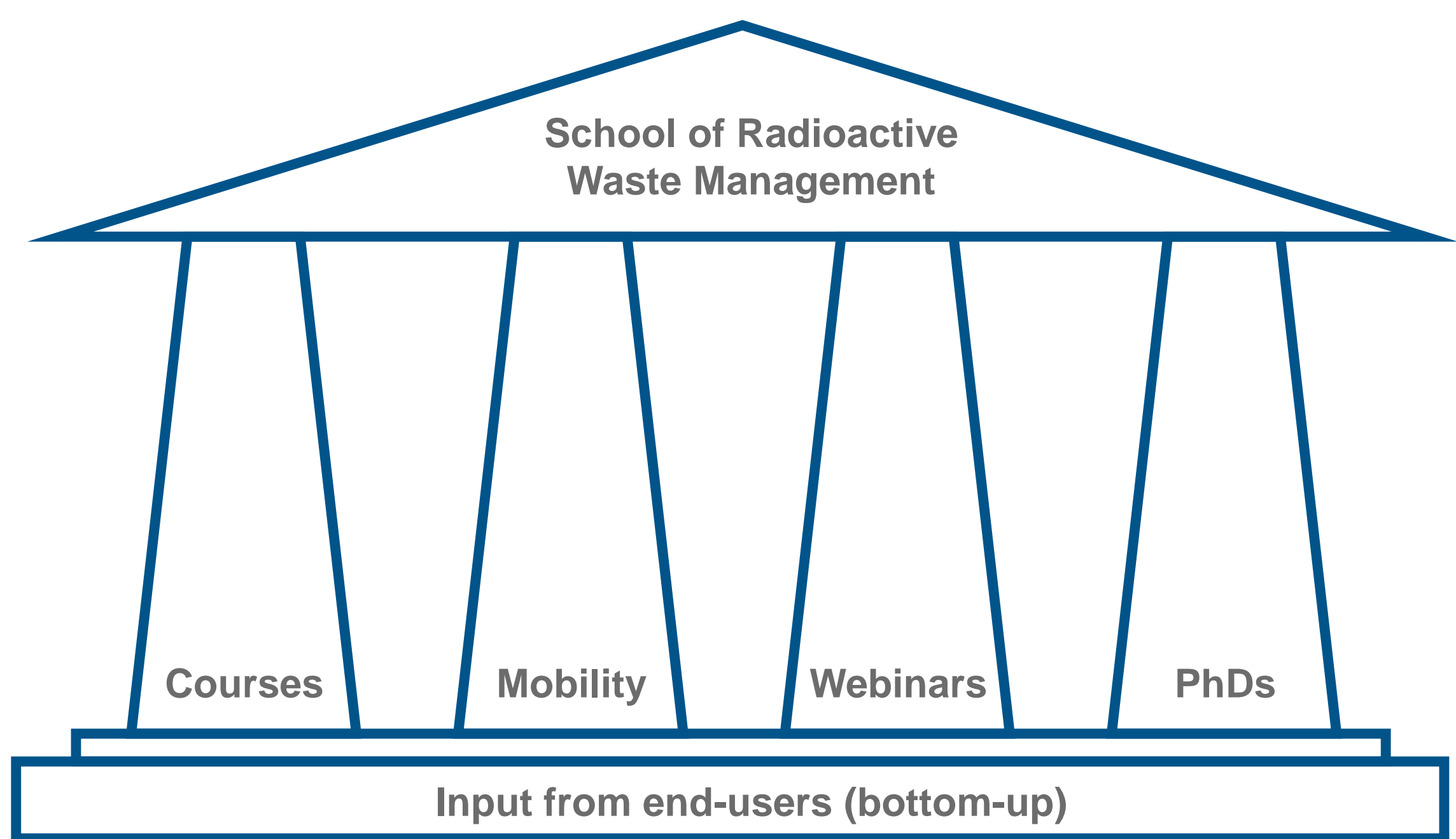




\section{EURAD SCHOOL OF RWM - NEEDS-DRIVEN TRAINING COURSES}

"Education and training are the totality of actions of increasing the knowledge, skills and attitudes of people to prepare them for doing a particular job"

- Needs-driven

- End-user feedback was gathered (March - May 2020)

- Training needs were identified (April 2021)

- Training courses organized in EURAD are:

- Based on end-user needs (and identified gaps in the Roadmap)

- In collaboration with RD\&D and Strategic Studies WPs

- Provide access to nuclear experience and know-how of the EURAD subject matter experts

- Main goal: effective knowledge transfer and competence building towards end-users 


\section{EURAD SCHOOL OF RWM - NEEDS-DRIVEN TRAINING COURSES}

- Implementation of training courses varies depending on the:

- Training needs

- Target audience

- Type of knowledge to be transferred (explicit vs implicit vs tacit)

- Desired competences to be acquired

- Learning outcomes

$\rightarrow$ Guidance document: 'Quality criteria and training specifications as a reference guide of requirements and expectations of the training courses to be developed'
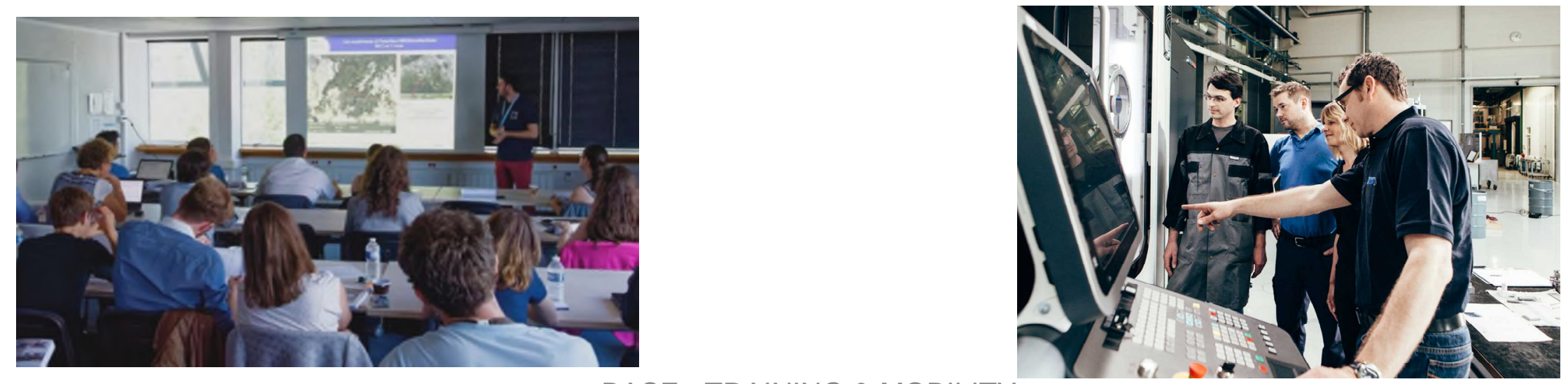


\section{EURAD SCHOOL OF RWM - NEEDS-DRIVEN TRAINING COURSES}

The Schools aims to provide context to its training course portfolio

- The field of RWM is very diverse and transdisciplinary

- E.g. chemistry, social interactions, long-term commitment, interactions with governments, etc.

- Each individual training course $=1$ piece of the puzzle

- Focus on one specific topic (e.g. deep geological disposal)

- The School's portfolio of training courses = collection of courses and topics:

- Deep geological disposal

- Interaction with Civil Society

- Legislation

- ...

$\rightarrow$ Portfolio provides context to help learners see 'the big picture'

$\rightarrow$ Ultimately leads to a higher level of competence of the learners 


\section{EURAD SCHOOL OF RWM - MOBILITY PROGRAMME}

- The EURAD Mobility Programme supports PhDs, post-docs and junior professionals in performing:

- Internships

- Technical visits

- Focussed mostly on implicit and tacit knowledge

- Based on learner needs

- Applicants can contact EURAD partners directly with specific questions

- List of infrastructures is available on School website: https://euradschool.eu/infrastructures/

- EURAD partners can offer internships on the School website 


\section{EURAD SCHOOL OF RWM - MOBILITY PROGRAMME}

- Applications and evaluations via an online platform (Evalato)

- https://pro.evalato.com/2185

- Intra-WP and cross-WP mobility actions

- Beneficiaries submit a detailed mission report

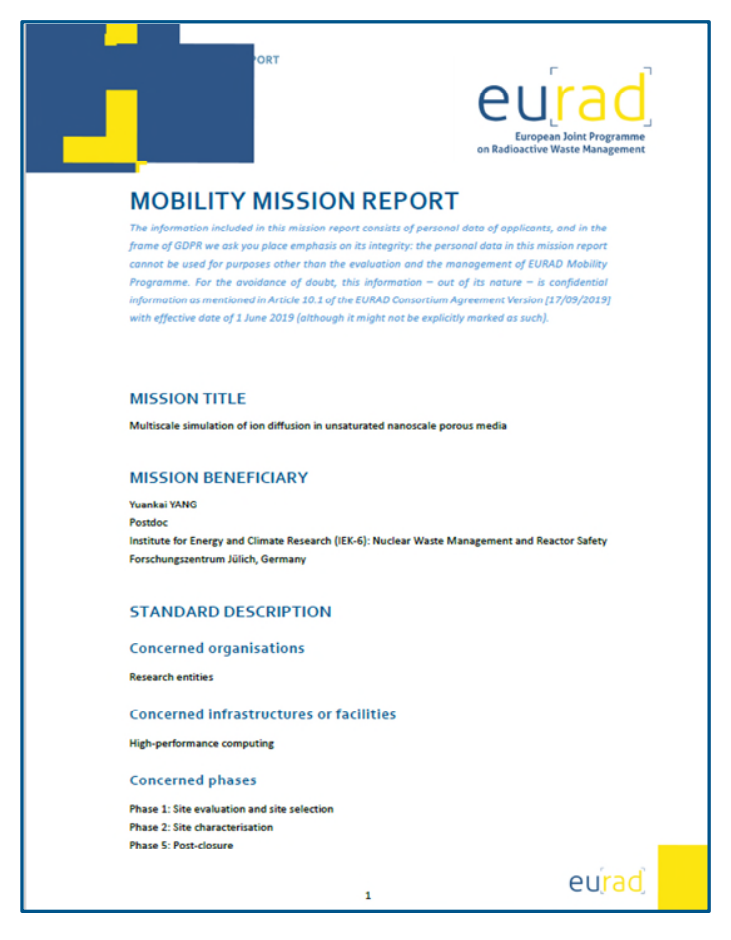

- Important for KM within EURAD and radioactive waste management in general

- Knowledge gained and created during mobility actions is recorded

- Mission reports are shared via the School's website, to assure access to the knowledge therein

- https://euradschool.eu/previous-mobility-actions/ 


\section{EURAD SCHOOL OF RWM - WEBINARS}

- The School organizes webinars on broad and specific topics by subject-matter experts, e.g.:

- Nuclear Knowledge Management

- PREDIS

- The US Nuclear Waste Management and Disposal Strategy

- Sharing knowledge with the entire EURAD community and beyond (e.g. PREDIS, IAEA, OECDNEA, ...)

- Recorded in order to preserve knowledge and facilitate dissemination (https://www.youtube.com/playlist?list=PLahXOQn-bremN911lEn0w8yAzQyuUR3ky) 


\section{EURAD SCHOOL OF RWM - WEBINARS}

\begin{tabular}{|l|c|c|}
\hline Title & \# attendees & $\begin{array}{l}\text { \# } \\
\text { (YouTube) }^{*}\end{array}$ \\
\hline $\begin{array}{l}\text { Synergies of EURAD with the PREDIS project addressing pre-disposal waste } \\
\text { treatment }\end{array}$ & 30 & 55 \\
\hline News from the German Site Selection Procedure & 19 & 74 \\
\hline Celebrating 20 years of the IGSC & 45 & 31 \\
\hline Knowledge Management in Nuclear Organizations & 22 & 20 \\
\hline $\begin{array}{l}\text { The IGD-TP: European waste management organisations coordinating } \\
\text { international R\&D activities }\end{array}$ & 19 & 52 \\
\hline $\begin{array}{l}\text { The next-generation scientific research for the safe management of radwaste - } \\
\text { EURADSCIENCE }\end{array}$ & 75 & 5 \\
\hline Steps for Sharing (ERDO Association) & 44 & 16 \\
\hline The SITEX.Network & 53 & 8 \\
\hline EC-JRC activities on RWM and decommissioning & 51 & 10 \\
\hline US Nuclear Waste Management and Disposal Strategies & 107 & 14 \\
\hline${ }^{*}$ As of October 14 ${ }^{\text {th } 2021}$ & & \\
\hline
\end{tabular}




\section{EURAD SCHOOL OF RWM - SUPPORT THE PHD COMMUNITY}

- The School wants to support the EURAD PhD community by providing:

- Information on available/upcoming courses

- The possibility to perform mobility actions

- An overview of all PhD research performed in EURAD (https://euradschool.eu/overview-of-phds/)

- A list of events of interest for PhD students

- A discussion forum (https://forum.euradschool.eu/)

- The aim is to foster a community between the PhD students 


\section{EURAD SCHOOL OF RWM AND KNOWLEDGE MANAGEMENT \& NETWORKING PROGRAMME}

- Training courses:

- Signposted on the Roadmap and fulfil end-users' needs

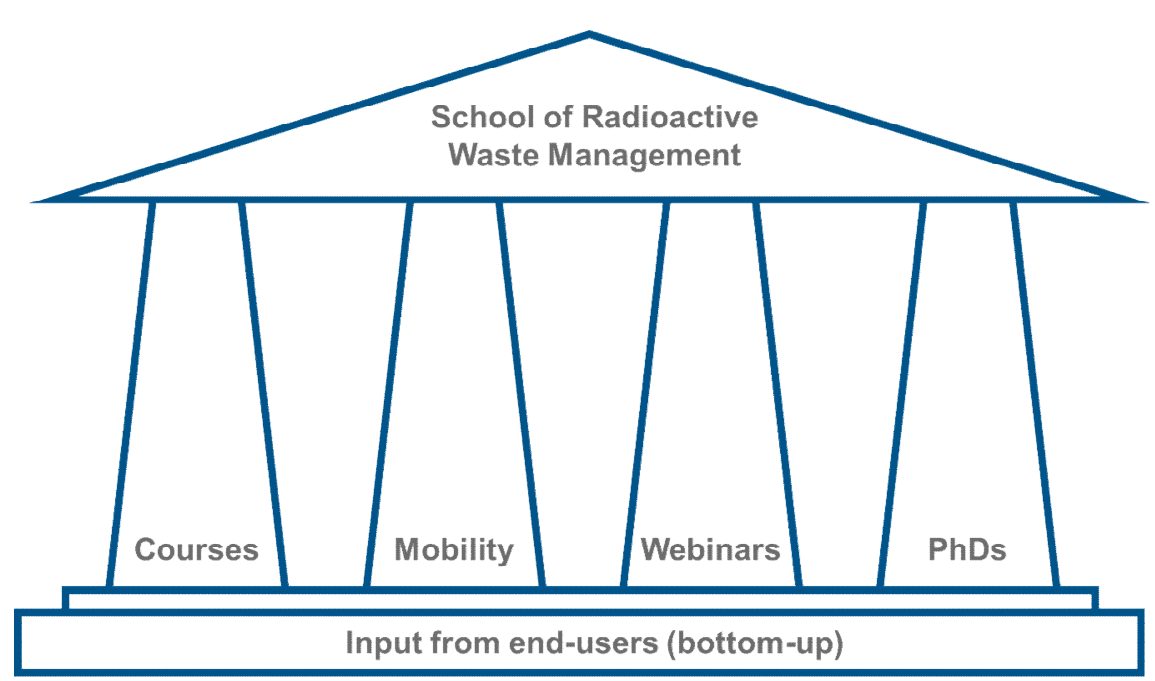

- State-of-the-Art knowledge and expertise as input (WP11+12)

- Mobility Programme:

- Sharing and obtaining tacit and implicit knowledge in the EURAD community (e.g. through access to dedicated infrastructures)

- Mission reports are made publically available and are linked to EURAD WPs, Themes and phases of a disposal programme

- Webinars:

- Open to all, on a wide variety of topics

- Recordings are publically available

- PhDs

- Foster a community and stimulate interactions between students and experts 


\section{eurad \\ European Joint Programme}

\section{QUESTIONS?}

\section{Niels Belmans (nbelmans@sckcen.be)}

The project leading to this application has received funding from the European Union's Horizon 2020 research and innovation programme under grant agreement $n^{\circ} 847593$.

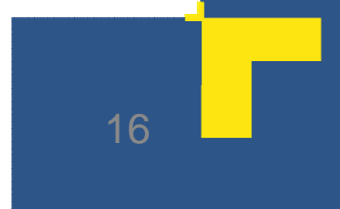

